\title{
Teaching Intermediate Macroeconomics using the 3-Equation Model
}

\author{
Wendy Carlin and David Soskice
}

Much teaching of intermediate macroeconomics uses the $I S-L M-A S$ or $A D$ $A S$ approach. This is far removed both from the practice of interest rate setting, inflation-targeting central banks and from the models that are taught in graduate courses. Modern monetary macroeconomics is based on what is increasingly known as the 3-equation New Keynesian model: $I S$ curve, Phillips curve and interest ratebased monetary policy rule $(I S-P C-M R)$. This is the basic analytical structure of Michael Woodford's book Interest and Prices published in 2003 and, for example, of the widely cited paper "The New Keynesian Science of Monetary Policy" by Clarida et al. published in the Journal of Economic Literature in 1999. A recent graduate textbook treatment is Gali (2008). Much of this literature is inaccessible to undergraduates and non-specialists. Our aim is to show how this divide can be bridged in a way that retains the tractability and policy-friendliness of the old approach yet fits the institutional realities of contemporary policy-making and opens the way to the more advanced literature.

Our contribution is to develop a version of the 3-equation model that can be taught to undergraduate students and can be deployed to analyze a broad range of policy issues, including the recent credit/banking crisis and the oil and commodities price shock. ${ }^{1}$ It can be taught using diagrams and minimal algebra. The $I S$ diagram is placed vertically above the Phillips diagram, with the monetary rule shown in the latter along with the Phillips curves. We believe that our $I S-P C-M R$ graphical analysis is particularly useful for explaining the optimizing behaviour of the central bank. Users can see and remember readily where the key relationships come from and are therefore able to vary the assumptions about the behaviour of the policymaker or the private sector. In order to use the model, it is necessary to think about the economics behind the processes of adjustment. One of the reasons $I S-L M-A S$ got a bad name is that it too frequently became an exercise in mechanical curveshifting: students were often unable to explain the economic processes involved in moving from one equilibrium to another. In the framework presented here, in order to work through the adjustment process, the student has to engage in the same forward-looking thinking as the policy-maker.

The model we propose for teaching purposes is New Keynesian in its 3-equation structure and its modelling of a forward-looking optimizing central bank. A significant problem for most students in the more formal versions of the New Keynesian model is the assumption that both households (in the IS equation) and price-setting

\footnotetext{
${ }^{1}$ This chapter is based on a section of Carlin and Soskice (2005).
} 
firms (in the Phillips curve) are forward looking. Our approach focuses just on a forward-looking Central Bank (in the Monetary or Taylor Rule) but does not incorporate forward-looking behavour in either the $I S$ curve or the Phillips curve. ${ }^{2}$

\section{The 3-Equation Model}

In this section, we set out the Carlin-Soskice (C-S) simplified version of the 3 equation model to show how it can be taught to undergraduates. Before showing how the central bank's problem-solving can be illustrated in a diagram, we set out the algebra.

\subsection{Equations}

The 3 equations are the IS equation $y_{1}=A-a r_{0}$ in which real income $y$ is a positive function of autonomous expenditure $A$ and a negative function of the real interest rate $r$; the Phillips curve $\pi_{1}=\pi_{0}+\alpha\left(y_{1}-y_{e}\right)$, where $\pi$ is the rate of inflation and $y_{e}$, equilibrium output; and the central bank's Monetary Rule. Equilibrium output is the level of output associated with constant inflation. In a world of imperfect competition it reflects the mark-up and structural features of the labour market and welfare state. ${ }^{3}$ We shall see that in order to make its interest rate decision, an optimizing central bank must take into account the lag in the effect of a change in the interest rate on output — the so-called policy lag — and any lag in the Phillips curve from a change in output to inflation. The key lags in the system relevant to the central bank's interest rate decision are shown in Fig. 1. In the $I S$ curve, the choice of interest rate in period zero $r_{0}$ will only affect output next period $y_{1}$ as it takes time for interest rate changes to feed through to expenditure decisions. In the Phillips curve, this period's inflation $\pi_{1}$ is affected by the current output gap $y_{1}-y_{e}$ and by last period's inflation $\pi_{0}$. The latter assumption of inflation persistence can be justified in terms of lags in wage- and or price-setting or by reference to backward-looking expectations.

The central bank minimizes a loss function, where the government requires it to keep next period's inflation close to the target whilst avoiding large output fluctuations:

$$
L=\left(y_{1}-y_{e}\right)^{2}+\beta\left(\pi_{1}-\pi^{T}\right)^{2} . \quad \text { (Central Bank loss function) }
$$

Any deviation in output from equilibrium or inflation from target - in either direction - produces a loss in utility for the central bank. The lag structure of the

\footnotetext{
${ }^{2}$ Both extensions are provided in Chapter 15 of Carlin and Soskice (2006).

${ }^{3} \mathrm{~A}$ more detailed discussion is provided in Carlin and Soskice (2006) Chapters 2, 4 and 15.
} 


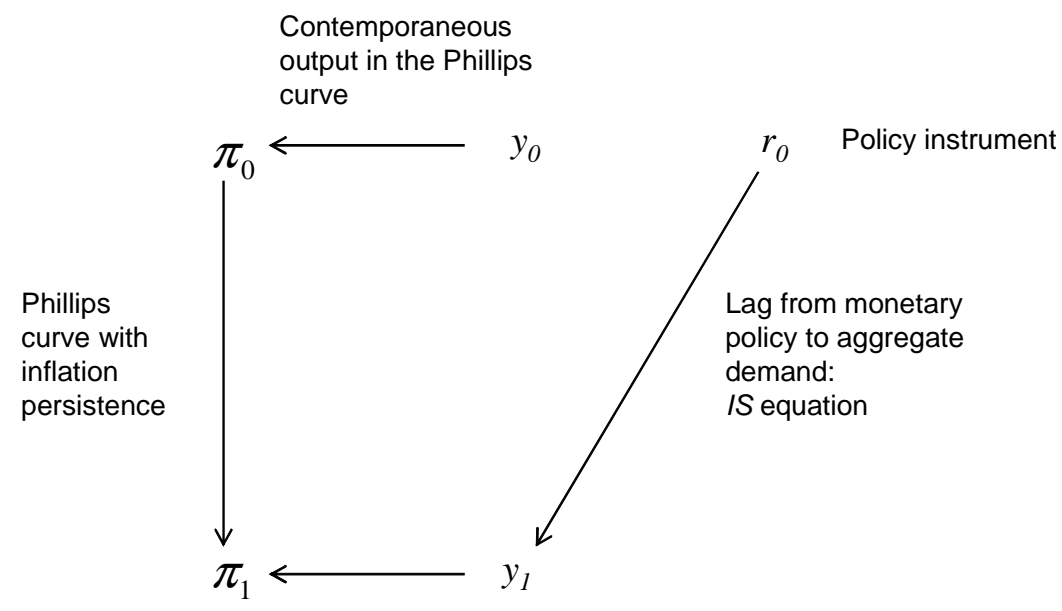

Figure 1: The lag structure in the $\mathrm{C}-\mathrm{S}$ 3-equation model

model explains why it is $\pi_{1}$ and $y_{1}$ that feature in the central bank's loss function: by choosing $r_{0}$, the central bank determines $y_{1}$, and $y_{1}$ in turn determines $\pi_{1}$. This is illustrated in Fig. 1. The critical parameter in the central bank's loss function is $\beta$ : $\beta>1$ will characterize a central bank that places less weight on output fluctuations than on deviations in inflation, and vice versa. A more inflation-averse central bank is characterized by a higher $\beta$.

The central bank optimizes by minimizing its loss function subject to the Phillips curve:

$$
\pi_{1}=\pi_{0}+\alpha\left(y_{1}-y_{e}\right) . \quad \text { (Inertial Phillips curve: } P C \text { equation) }
$$

By substituting the Phillips curve equation into the loss function and differentiating with respect to $y_{1}$ (which, as we have seen in Fig. 1, the central bank can choose by setting $r_{0}$ ), we have:

$$
\frac{\partial L}{\partial y_{1}}=\left(y_{1}-y_{e}\right)+\alpha \beta\left(\pi_{0}+\alpha\left(y_{1}-y_{e}\right)-\pi^{T}\right)=0 .
$$

Substituting the Phillips curve back into this equation gives:

$$
\left(y_{1}-y_{e}\right)=-\alpha \beta\left(\pi_{1}-\pi^{T}\right) . \quad \text { (Monetary rule: } M R-A D \text { equation) }
$$


This equation is the 'optimal' equilibrium relationship in period 1 between the inflation rate chosen indirectly and the level of output chosen directly by the central bank in the current period 0 to maximize its utility given its preferences and the constraints it faces.

Here is the logic of the central bank's position in period 0: it knows $\pi_{0}$ and hence it can work out via the Phillips curve (since $\pi_{1}=\pi_{0}+\alpha \cdot\left(y_{1}-y_{e}\right)$ ) what level of $y_{1}$ it has to get to - by setting the appropriate $r_{0}$ in the current period for this equilibrium relation to hold. We shall see that there is a natural geometric way of highlighting this logic.

We can either talk in terms of the Monetary Rule or alternatively the Interest Rate Rule (sometimes called the optimal Taylor Rule), which shows the short term real interest rate relative to the 'stabilising' or 'natural' real rate of interest, $r_{S}$, that the central bank should set now in response to a deviation of the current inflation rate from target. To find out the interest rate that the central bank should set in the current period, as well as to derive $r_{S}$ we need to use the $I S$ equation. The central bank can set the nominal short-term interest rate directly, but since the expected rate of inflation is given in the short run, the central bank is assumed to be able to control the real interest rate indirectly. We make use here of the Fisher equation, $i \approx r+\pi^{E}$. The $I S$ equation incorporates the lagged effect of the interest rate on output:

$$
y_{1}=A-a r_{0} .
$$

A key concept is the stabilising interest rate $r_{S}$, which is the interest rate that produces equilibrium output. This is defined by

$$
y_{e}=A-a r_{S} .
$$

So subtracting this from the $I S$ equation we can rewrite the $I S$ equation in output gap form as:

$$
y_{1}-y_{e}=-a\left(r_{0}-r_{S}\right) . \quad \text { (IS equation, output gap form) }
$$

If we substitute for $\pi_{1}$ using the Phillips curve in the $M R$ - $A D$ equation, we get

$$
\begin{aligned}
\pi_{0}+\alpha\left(y_{1}-y_{e}\right)-\pi^{T} & =-\frac{1}{\alpha \beta}\left(y_{1}-y_{e}\right) \\
\pi_{0}-\pi^{T} & =-\left(\alpha+\frac{1}{\alpha \beta}\right)\left(y_{1}-y_{e}\right)
\end{aligned}
$$

and if we now substitute for $\left(y_{1}-y_{e}\right)$ using the $I S$ equation, we get

$$
\left(r_{0}-r_{S}\right)=\frac{1}{a\left(\alpha+\frac{1}{\alpha \beta}\right)}\left(\pi_{0}-\pi^{T}\right) . \quad \text { (Interest-rate rule, } I R \text { equation) }
$$


As a simple case, let $a=\alpha=\beta=1$, so that

$$
\left(r_{0}-r_{S}\right)=0.5\left(\pi_{0}-\pi^{T}\right) .
$$

This tells the central bank how to adjust the interest rate (relative to the stabilizing interest rate) in response to a deviation of inflation from its target.

By setting out the central bank's problem in this way, we have identified the key role of forecasting: the central bank must forecast the Phillips curve and the $I S$ curve it will face next period. Although the central bank observes the shock in period zero and calculates its impact on current output and next period's inflation, it cannot offset the shock in the current period because of the lagged effect of the interest rate on aggregate demand. We therefore have a 3-equation model with an optimizing central bank in which $I S$ shocks affect output. As we shall see in Section 1.2, the $M R-A D$ equation is the preferred formulation of policy behaviour in the graphical illustration of the model. We return to the relationship between the $M R-A D$ equation and the Taylor Rule in Section 3.

\subsection{Diagram: the example of an $I S$ shock}

We shall now explain how the 3-equation model can be set out in a diagram. A graphical approach is useful in bringing out the economic intuition at the heart of the model. It allows students to work through the forecasting exercise of the central bank and to follow the adjustment process as the optimal monetary policy is implemented.

The first step is to present two of the equations of the 3-equation model. In the lower part of Fig. 2, the vertical Phillips curve at the equilibrium output level, $y_{e}$, is shown. We think of labour and product markets as being imperfectly competitive so that the equilibrium output level is where both wage- and price-setters make no attempt to change the prevailing real wage or relative prices. Each Phillips curve is indexed by the pre-existing or inertial rate of inflation, $\pi^{I}=\pi_{-1}$. shown in Fig. 2, the economy is in a constant inflation equilibrium at the output level of $y_{e}$; inflation is constant at the target rate of $\pi^{T}$. Fig. 2 shows the $I S$ equation in the upper panel: the stabilizing interest rate, $r_{S}$, will produce a level of aggregate demand equal to equilibrium output, $y_{e}$. We now need to combine the three elements: IS curve, Phillips curve and the Central Bank's loss function to show how the central bank formulates monetary policy. To see the graphical derivation of the monetary rule equation (labelled $M R-A D$ ), it is useful to begin with an example.

In Fig. 3, we assume that as a consequence of an $I S$ shock the economy is initially at point $A$ with output above equilibrium, i.e. $y>y_{e}$, and inflation of 

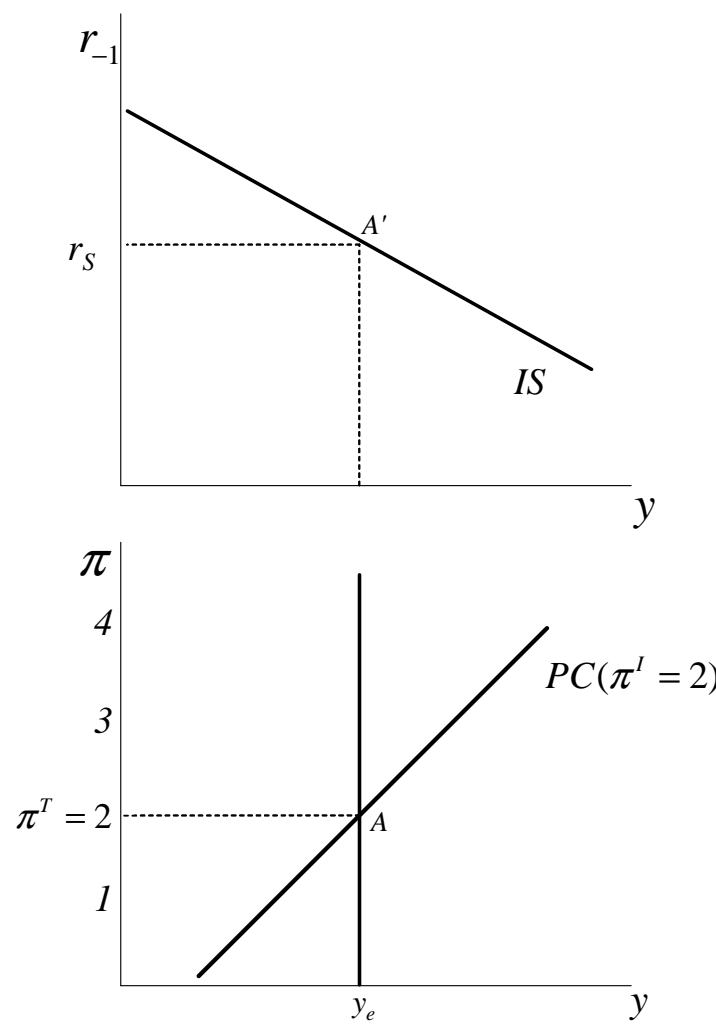

Figure 2: $I S$ and $P C$ curves

$4 \%$ above the $2 \%$ target. The central bank's job is to set the interest rate, $r_{0}$, in response to this new information about economic conditions. In order to do this, it must first make a forecast of the Phillips curve next period, since this will show the menu of output-inflation pairs that it can choose from by setting the interest rate now. Given that inflation is inertial, its forecast of the Phillips curve in period one will be $P C\left(\pi^{I}=4 \%\right)$ as shown by the dashed line in the Phillips curve diagram. The only points on this Phillips curve with inflation below $4 \%$ entail lower output. Hence, disinflation will be costly.

How does the central bank make its choice from the combinations of inflation and output along the forecast Phillips curve $\left(P C\left(\pi^{I}=4 \%\right)\right)$ ? Its choice will depend on its preferences: the higher is $\beta$ the more averse it is to inflation and the more it will want to reduce inflation by choosing a larger output gap. We show in the appendix how the central bank's loss function can be represented graphically by 


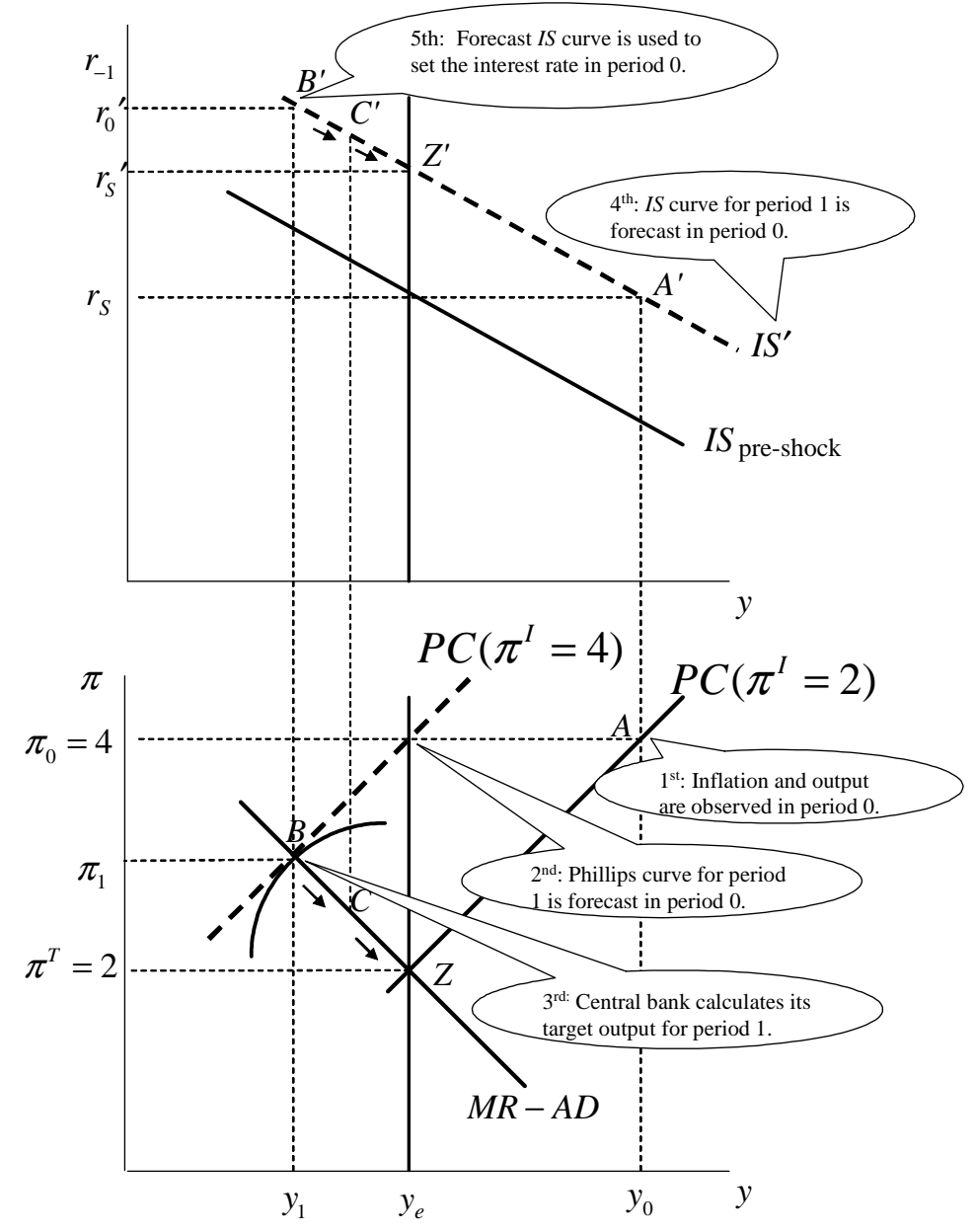

Figure 3: How the central bank decides on the interest rate 
loss circles or ellipses. In Fig. 3, the central bank will choose point $B$ at the tangency between its 'indifference curve' and the forecast Phillips curve: this implies that its desired output level in period one is $y_{1}$. In other words, $y_{1}$ is the central bank's aggregate demand target for period 1 as implied by the monetary rule. The $M R-A D$ line joins point $B$ and the zero loss point at $Z$ where inflation is at target and output is at equilibrium. The fourth step is for the central bank to forecast the $I S$ curve for period one. In the example in Fig. 3 the forecast $I S$ curve is shown by the dashed line. With this $I S$ curve, if an interest rate of $r_{0}^{\prime}$ is set now, the level of output in period one will be $y_{1}$ as desired.

To complete the example, we trace through the adjustment process. Following the increase in the interest rate, output falls to $y_{1}$ and inflation falls. The central bank forecasts the new Phillips curve, which goes through point $C$ in the Phillips diagram and it will follow the same steps to adjust the interest rate downwards so as to guide the economy along the $I S$ curve from $C^{\prime}$ to $Z^{\prime}$. Eventually, the objective of inflation at $\pi^{T}=2 \%$ is achieved and the economy is at equilibrium unemployment, where it will remain until a new shock or policy change arises. The $M R$ - $A D$ line shows the optimal inflation-output choices of the central bank, given the Phillips curve constraint that it faces.

An important pedagogical question is the name to give the monetary rule equation when we show it in the $\pi y$-diagram. What it tells the central bank at $t=0$ is the output level that it needs to achieve in $t=1$ if it is to minimize the loss function, given the forecast Phillips curve. Since we are explaining the model from the central bank's viewpoint at $t=0$, what we want to convey is that the downwardsloping line in the $\pi y$-diagram shows the aggregate demand target at $t=1 \mathrm{implied}$ by the monetary rule. We therefore use the label $M R-A D{ }^{4}$

The $M R-A D$ curve is shown in the Phillips rather than in the $I S$ diagram because the essence of the monetary rule is to identify the central bank's best policy response to any shock. Both the central bank's preferences shown graphically by the indifference curve (part of the loss circle or ellipse) and the trade-off it faces between output and inflation appear in the Phillips diagram. Once the central bank has calculated its desired output response by using the forecast Phillips curve, it is straightforward to go to the $I S$ diagram and discover what interest rate must be set in order to achieve this level of aggregate demand.

\footnotetext{
${ }^{4}$ It would be misleading to label it $A D$ thus implying that it is the actual $A D$ curve in $\pi_{1} y_{1}-$ space because the actual $A D$ curve will include any aggregate demand shock in $t=1$. If aggregate demand shocks in $t=1$ are included, the curve ceases to be the curve on which the central bank bases its monetary policy in $t=0$. On the other hand if an aggregate demand shock in $t=1$ is excluded - so that the central bank can base monetary policy on the curve — then it is misleading to call it the $A D$ schedule; students would not unreasonably be surprised if an $A D$ schedule did not shift in response to an $A D$ shock.
} 


\section{Using the Graphical Model}

We now look briefly at different shocks so as to illustrate the role the following six elements play in their transmission and hence in the deliberations of policy-makers in the central bank:

1. the inflation target, $\pi^{T}$

2. the central bank's preferences, $\beta$

3. the slope of the Phillips curve, $\alpha$

4. the interest sensitivity of aggregate demand, $a$

5. the equilibrium level of output, $y_{e}$

6. the stabilizing interest rate, $r_{S}$.

A temporary aggregate demand shock is a one-period shift in the $I S$ curve, whereas a permanent aggregate demand shock shifts the $I S$ curve and hence $r_{S}$, the stabilizing interest rate, permanently. An inflation shock is a temporary (oneperiod) shift in the short-run Phillips curve. This is sometimes referred to as a temporary aggregate supply shock. An aggregate supply shock refers to a permanent shift in the equilibrium level of output, $y_{e}$. This shifts the vertical Phillips curve.

\subsection{IS shock: temporary or permanent?}

In Fig. 3, we analyzed an $I S$ shock - but was it a temporary or a permanent one? In order for the Central Bank to make its forecast of the $I S$ curve, it has to decide whether the shock that initially caused output to rise to $y_{0}$ is temporary or permanent. The terms 'temporary' and 'permanent' should be interpreted from the perspective of the central bank's decision-making horizon. In our example, the central bank took the view that the shock would persist for another period, so it was necessary to raise the interest rate to $r_{0}^{\prime}$ above the new stabilizing interest rate, $r_{S}^{\prime}$. Had the central bank forecast that the $I S$ would revert to the pre-shock $I S$, then it would have initially raised the interest rate by less since the stabilizing interest rate would have remained equal to $r_{S}$, i.e. its chosen interest rate would have been on the $I S_{\text {pre-shock }}$ curve in Fig. 3 rather than on the $I S^{\prime}$ curve. This highlights one of the major forecasting problems faced by the central bank. 


\subsection{Supply shock}

One of the key tasks of a basic macroeconomic model is to help illuminate how the main variables are correlated following different kinds of shocks. We can appraise the usefulness of the $I S-P C-M R$ model in this respect by looking at a positive aggregate supply shock and comparing the optimal response of the central bank and hence the output and inflation correlations with those associated with an aggregate demand shock. A supply shock results in a change in equilibrium output and therefore a shift in the vertical Phillips curve. It can arise from changes that affect wage- or price-setting behaviour such as a structural change in wage-setting arrangements, a change in taxation or in unemployment benefits or in the strength of product market competition, which alters the mark-up.

Fig. 4 shows the analysis of a positive supply-side shock, which raises equilibrium output from $y_{e}$ to $y_{e}^{\prime}$. The vertical Phillips curve shifts to the right as does the short-run Phillips curve corresponding to inflation equal to the target (shown by the $\left.P C\left(\pi^{I}=2, y_{e}^{\prime}\right)\right)$. The first consequence of the supply shock is a fall in inflation (from $2 \%$ to zero) as the economy goes from $A$ to $B$. To decide how monetary policy should respond to this, the central bank forecasts the Phillips curve constraint $\left(P C\left(\pi^{I}=0, y_{e}^{\prime}\right)\right)$ for next period and chooses its optimal level of output as shown by point $C$. To raise output to this level, it is necessary to cut the interest rate in period zero to $r^{\prime}$ as shown in the $I S$ diagram. (Note that the stabilizing interest rate has fallen to $r_{S}^{\prime}$.) The economy is then guided along the $M R$-AD curve to the new equilibrium at $Z$. The positive supply shock is associated initially with a fall in inflation and a rise in output - in contrast to the initial rise in both output and inflation in response to the aggregate demand shock.

\subsection{Applying the model to recent macro-economic events}

The economic conjuncture from August 2007 poses a good test for a macro model at the intermediate level. Two major developments affected the world economy: the credit and housing crisis emanating from the sub-prime lending behaviour of US banks and the dramatic increase in oil and commodities prices. We look first at each development in turn. The credit crisis is a negative aggregate demand shock: credit became more expensive and some classes of borrowers were excluded entirely from the market. Hence, at a given central bank interest rate, $r$, interest-sensitive spending is lower and the $I S$-curve is shifted to the left. As we have seen, this requires the central bank to reduce the interest rate in order to guide the economy back to equilibrium output at target inflation. The use of temporary expansionary fiscal measures as adopted in the US in 2008 will — if successful in boosting consumption expenditure - also help to offset the leftward shift of the $I S$-curve and reduce 


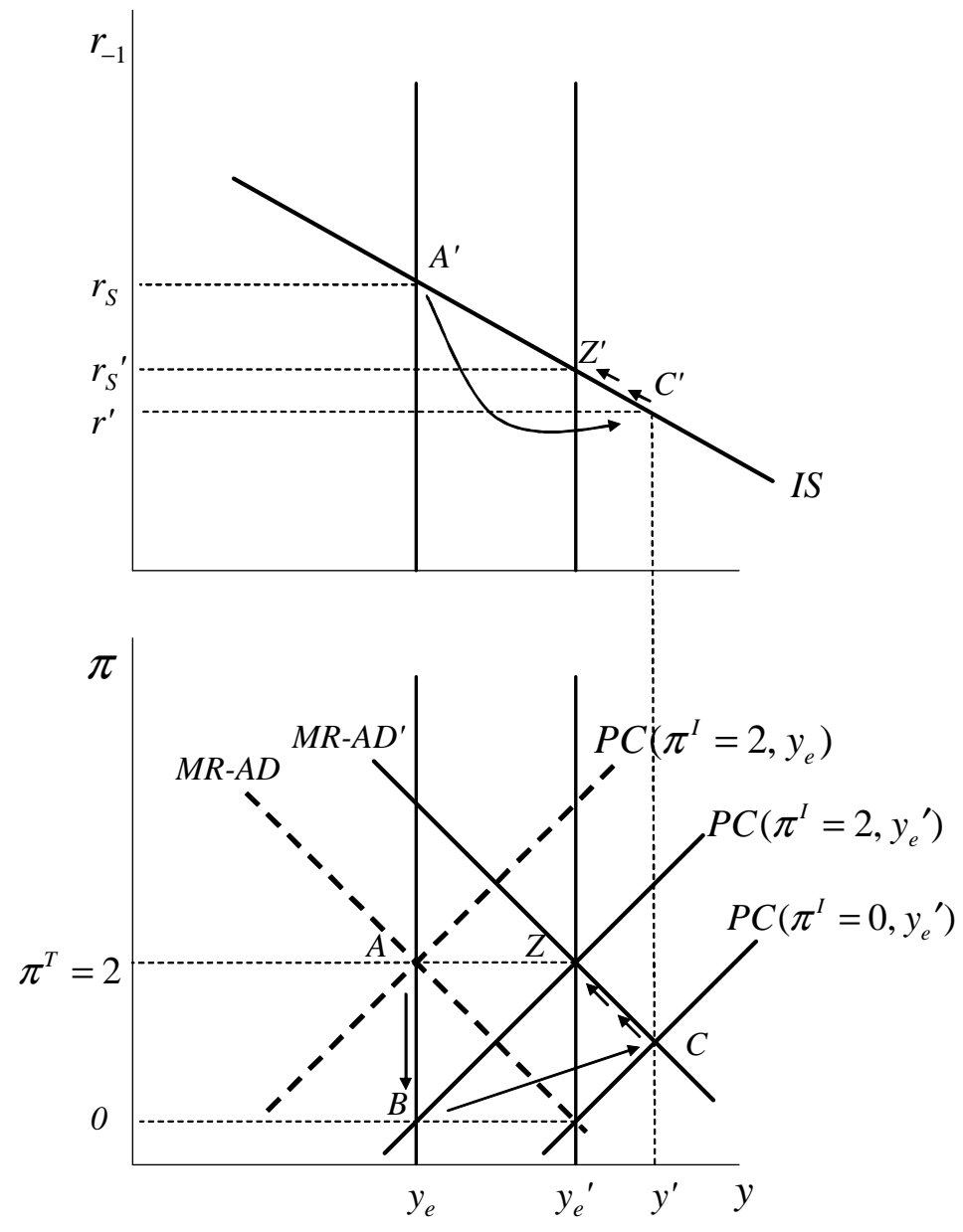

Figure 4: The response of the central bank to a positive supply-side shock, a rise in equilibrium output 
the extent to which the interest rate has to be cut. The simplest way of modeling this is as an increase in the autonomous component of aggregate demand captured in the $A$ term in the $I S$ equation.

Analysis of the oil and commodity price shock can also be undertaken using the 3-equation model. There are two elements to the shock: its implications for aggregate demand and for the supply-side. For countries that are net importers of oil and commodities, the price increase represents a negative aggregate demand shock: at any real interest rate, aggregate demand is depressed by the higher import bill and the $I S$-curve shifts to the left. The simplest way of depicting the supplyside effects of the oil price rise is as a temporary inflation shock: the Phillips curve is shifted upwards for one period. An inflation shock requires the central bank to raise the interest rate since a spell of output below equilibrium is required to squeeze the increased inflation out of the system. In the context of an oil price shock, since aggregate demand is depressed by the higher import bill, the central bank will need to raise the interest rate by less than it otherwise would.

In the circumstances of 2008 , the central bank is faced with a forecast deterioration of both constituents of its loss function. Aggregate demand and output are depressed both by the credit crisis and the oil shock, which points to a cut in the interest rate. However, the inflation shock points to the need for the interest rate to be raised. The 3-equation model illustrates the conflicting pressures on the central bank and highlights that whether it should raise or lower the interest rate depends on its judgement of the relative size and persistence of the $I S$ and inflation shock effects.

The modeling of the supply-side consequences of an oil shock as a temporary inflation shock hinges on the willingness of wage- and or price-setters in the economy to accept the reduction in real income implied by the exogenous deterioration in the economy's terms of trade. Higher real oil and commodity prices mean that output per worker available for domestic agents is lower. If domestic profit margins and or domestic real wages do not adjust to this, then the oil shock represents a supply shock that reduces equilibrium output, rather than a temporary inflation shock. This can be modeled using the supply shock analysis presented above: the $M R-A D$ curve and the vertical Phillips curve shift to the left. The implications for the economy of a negative supply shock are more pessimistic than for an inflation shock because the inflation target can now only be met at higher equilibrium unemployment and lower output. In the contemporary discussion of the oil shock, the question has been discussed as to whether 'second round effects' have emerged. If wage and or price setters do not accept the reduction in real income associated with the shock, the Phillips curve for a given inertial inflation rate will shift upward as it is now indexed by the new higher equilibrium unemployment. This is a way of illustrating such second round effects. 
We use Fig. 5 to show how the combined effect of the credit crunch and the oil price shock can be modeled graphically. There are three panels: the labour market is introduced as the lowest panel, with the real consumption wage on the vertical axis. The utility of wage-setters is defined in terms of the real consumption wage, i.e. the money wage deflated by the consumer price index. Wage-setters' behaviour is shown by the positively sloped $W S$ curve: they require a higher real consumption wage at higher employment (output). A simple way of thinking about the wagesetting curve is that it represents a mark-up reflecting workers' bargaining power over the competitive labour supply curve, which slopes upward to reflect the disutility of work. By contrast, firms or price-setters care about their profits defined in terms of the product price. On the assumption of constant labour productivity and a constant mark-up, the price-setting curve is horizontal. It shows the real consumption wage that is consistent with firms getting their required profit margin, given labour productivity and the size of the wedge between the real consumption and product wages. ${ }^{5}$ The wedge will be affected by a change in the price of imported oil and commodities because this affects the difference between the consumer price index and the producer price index. An increase in the wedge caused by higher oil and commodity prices will be reflected in a downward shift in the price-setting real wage curve in Fig. 5 to $P S^{\prime}$.

In Fig. 5, we analyse the case in which wage and or price setters do not accept the reduction in available real income per worker implied by the higher oil prices. Had they done so, either the $W S$ curve would have shifted downwards to go through point $B$ or the $P S$ curve would have remained unchanged at $P S$ with profit margins squeezed (or some combination of the two). The failure of the real wage and profit claims of wage and price-setters to adjust (or adjust fully) means that the oil shock leads to a fall in equilibrium output: this is shown by the shift from $y_{e}$ to $y_{e}^{\prime}$ in Fig. 5 . The lower level of equilibrium output indicates that the only way constant inflation can prevail in the economy is to reduce the real wage claims of wage-setters by a higher level of unemployment.

As noted above, the $I S$ curve in Fig. 5 shifts to the left for two reasons - on the one hand because of the impact of the credit crisis on aggregate demand and on the other, because of the implications for aggregate demand of the higher prices of oil and commodities. For illustrative purposes, the combined effect is shown by $I S^{\prime}$. In the example shown in the diagram, the $I S$ shift is sufficiently large that the central bank does not have to change the interest rate in order to achieve its desired level of output $y^{\prime}$ on the $M R$ - $A D^{\prime}$ at point $C$, and is therefore at point $C^{\prime}$ on the $I S^{\prime}$ curve. The central bank will then lower the interest rate on the path from $C^{\prime}$ to

\footnotetext{
${ }^{5} \mathrm{~A}$ formal derivation of the price-setting curve to reflect imported materials is provided in Carlin and Soskice (2006) footnote 7, pp. 396-7.
} 
the new stabilizing interest rate, $r_{S}^{\prime}$. In the central panel, inflation will gradually fall back its target level ( $C$ to $Z$ ) and output will stabilize at the new lower equilibrium level (point $Z$ ). ${ }^{6}$

In Fig. 6, the combined effect of the credit crisis and oil shock is illustrated using the more optimistic assumption that there is no deterioration in equilibrium output. This is shown graphically in the lower panel, where in contrast to Fig. 5, there is a downward shift of the wage-setting curve to $W S^{\prime}$. This may be the result of an agreement amongst unions to exercise wage restraint or alternatively, if the wage-setting curve is vertical (e.g. inelastic labour supply), there will also be no change in equilibrium output. The impact of the oil shock on the supply side takes the form of a one-off upward shift in the Phillips Curve to $P C\left(\pi^{I}=2 \% ; \epsilon=2 \%\right)$, where $\epsilon$ is the inflation shock. This is illustrated in the middle panel. By comparing the middle panel of Fig. 5 with that of Fig. 6, one can see that in each case there is a new Phillips curve going through point $B$ with an inflation rate of $4 \%$ at the initial output level. As before, the effects on aggregate demand are illustrated by the shift of the $I S$ curve to $I S^{\prime}$. As a consequence of the combined shocks, output falls to $y^{\prime}$ and inflation drops from $4 \%$ to $1 \%$. The economy is at point $C$ in the middle panel. The central bank forecasts the new Phillips Curve to be the one labelled $P C\left(\pi^{I}=1 \%\right)$. It must therefore cut the interest rate (below $r_{S}^{\prime}$ in the upper panel) so as to steer the economy from point $D$ back to target inflation and equilibrium output at point $Z$, which coincides with the economy's starting point at $A$.

For both cases illustrated in Figs. 5 and 6, it is a useful exercise to experiment with a combination where the $I S$ shift is smaller relative to the Phillips Curve shift than the one shown. This highlights the debates in the various central banks around the world as to whether interest rates should be raised or lowered in response to the credit crisis and oil shock. In the example shown, the $I S$ shift is substantial and squeezes inflation hard; with a smaller negative $I S$ shock, the central bank would have to do more to eliminate the rise in inflation and a rise in interest rates would be observed.

We see that the initial consequences for the economy of the credit and oil crises are lower output and higher inflation in both of the cases illustrated in this section. Given the presence of an inflation-targeting central bank, target inflation is regained in each case but unless the implications for real incomes of the oil shock are accepted by private sector agents, a higher rate of unemployment will be required to ensure constant inflation at the target rate.

\footnotetext{
${ }^{6}$ Note that if the central bank does not recognize that the equilibrium level of output has fallen and continues to target an output level of $y_{e}$, the economy will end up at the intersection of vertical line above $y_{e}^{\prime}$ and the initial $M R$ - $A D$ curve. Inflation will be constant but it will be higher than the target rate. This is an example of so-called inflation bias and is examined in more depth in Carlin and Soskice (2005).
} 


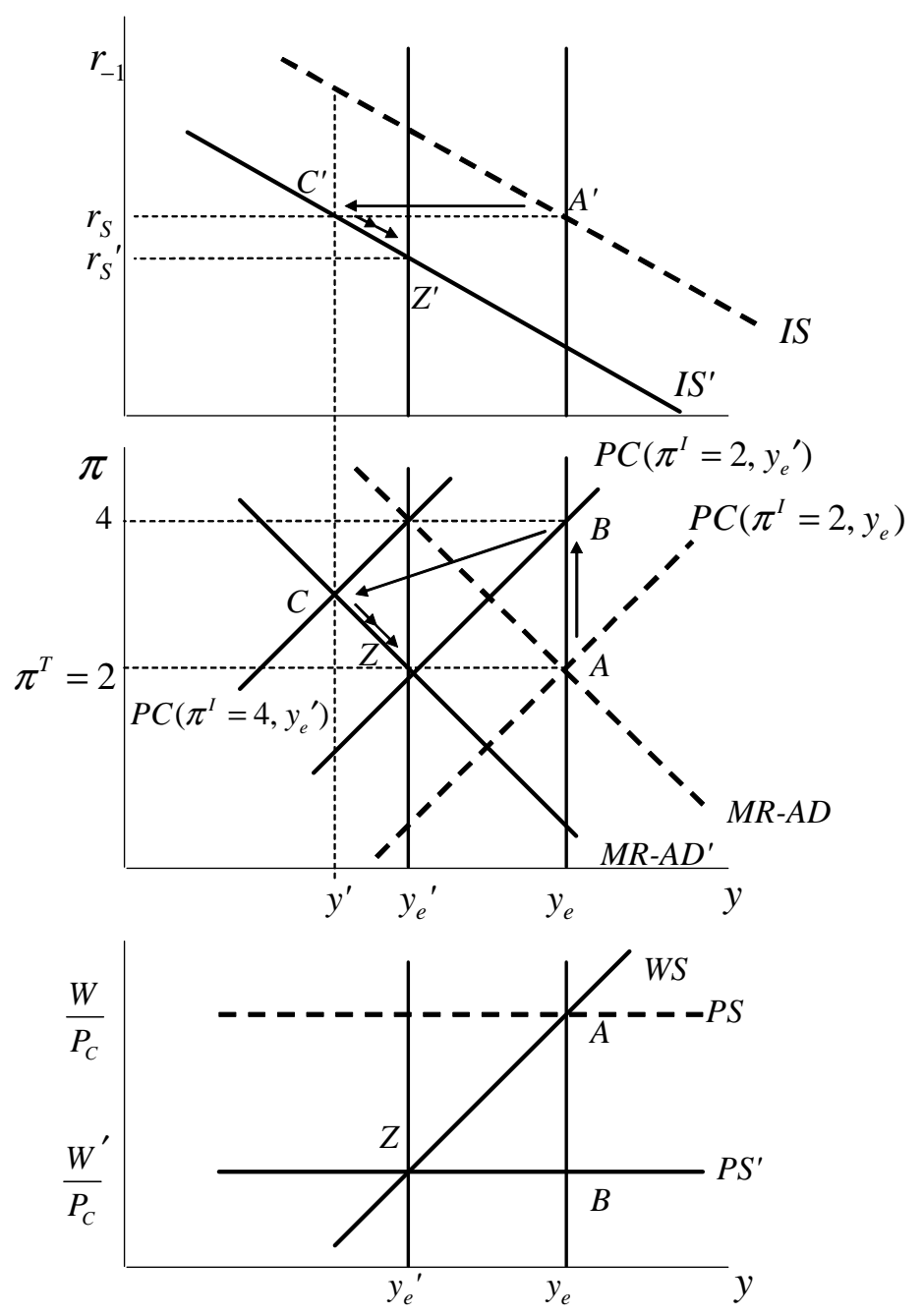

Figure 5: Combined Credit Crisis and Oil Price Shock: Lower Equilibrium Output 


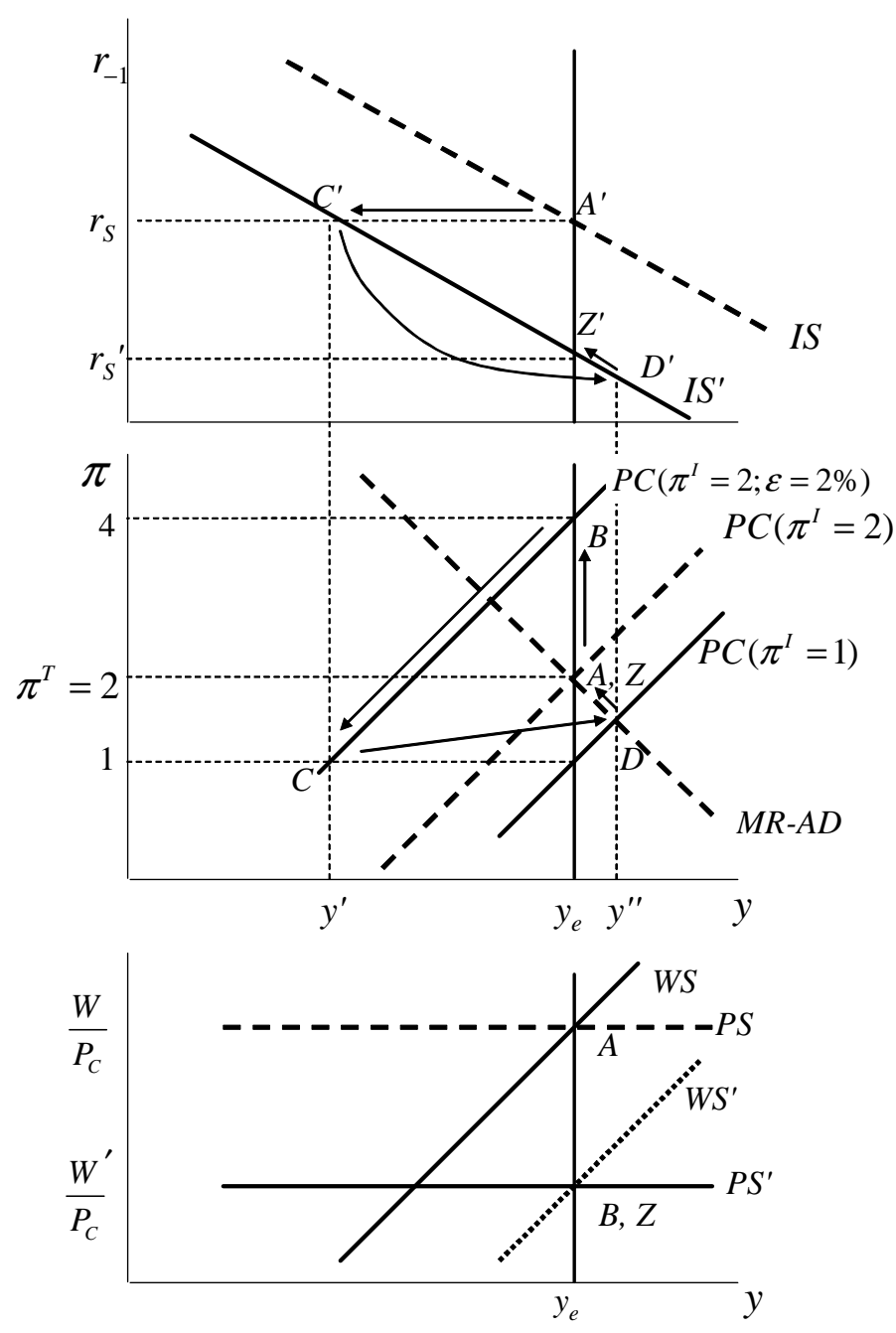

Figure 6: Combined Credit Crisis and Oil Price Shock: Unchanged Equilibrium Output 


\subsection{IS shock: the role of the interest-sensitivity of aggregate de- mand}

In the next experiment (Fig. 7), we keep the supply side of the economy and the central bank's preferences fixed and examine how the central bank's response to a permanent aggregate demand shock is affected by the sensitivity of aggregate demand to the interest rate. It is assumed that the economy starts off with output at equilibrium and inflation at the target rate of $2 \%$. The equilibrium is disturbed by a positive aggregate demand shock such as improved buoyancy of consumer expectations, which is assumed by the central bank to be permanent. Two postshock $I S$ curves are shown in the upper panel of Fig. 7: the more-interest sensitive one is the flatter one labelled $I S^{\prime \prime}$.

The consequence of output above $y_{e}$ is that inflation rises above target - in this case to $4 \%$ (point $B$ ). This defines the Phillips curve $\left(P C\left(\pi^{I}=4\right)\right.$ ) along which the central bank must choose its preferred point for the next period: point $C$. The desired level of aggregate demand depends only on the aspects of the economy depicted in the Phillips diagram, i.e. the supply side and the central bank's preferences and hence is the same for each economy. However, by going vertically up to the $I S$-diagram, we can see that the central bank must raise the interest rate by less in response to the shock if aggregate demand is rather responsive to a change in the interest rate (as illustrated by the flatter $I S$ curve).

\subsection{How central bank inflation aversion and the slope of the Phillips curve affect interest rate decisions}

To investigate how structural features of the economy such as the degree of inflation aversion of the central bank and the responsiveness of inflation to the output gap impinge on the central bank's interest rate decision, we look at the central bank's response to an inflation shock. A one-period shift in the Phillips curve could occur as a result, for example, of an agricultural disease outbreak that temporarily interrupts supply and pushes inflation above the target level.

We focus attention on the consequences for monetary policy of different degrees of inflation aversion on the part of the central bank $(\beta)$ and on the responsiveness of inflation to output as reflected in the slope of the Phillips curve $(\alpha)$. We assume the economy is initially in equilibrium with inflation at the central bank's target rate of $2 \%$ and experiences a sudden rise in inflation to $4 \%$. The Phillips curve in Fig. 8 shifts to $P C\left(\pi^{I}=4 \%\right)$.

From the $M R$ - $A D$ equation $\left(\left(y_{1}-y_{e}\right)=-\alpha \beta\left(\pi_{1}-\pi^{T}\right)\right)$ and from the geometry in Fig. 8, it is clear that if the indifference curves are circles (i.e. $\beta=1$ ) and if the Phillips curve has a gradient of one (i.e. $\alpha=1$ ), the $M R-A D$ line is downward 


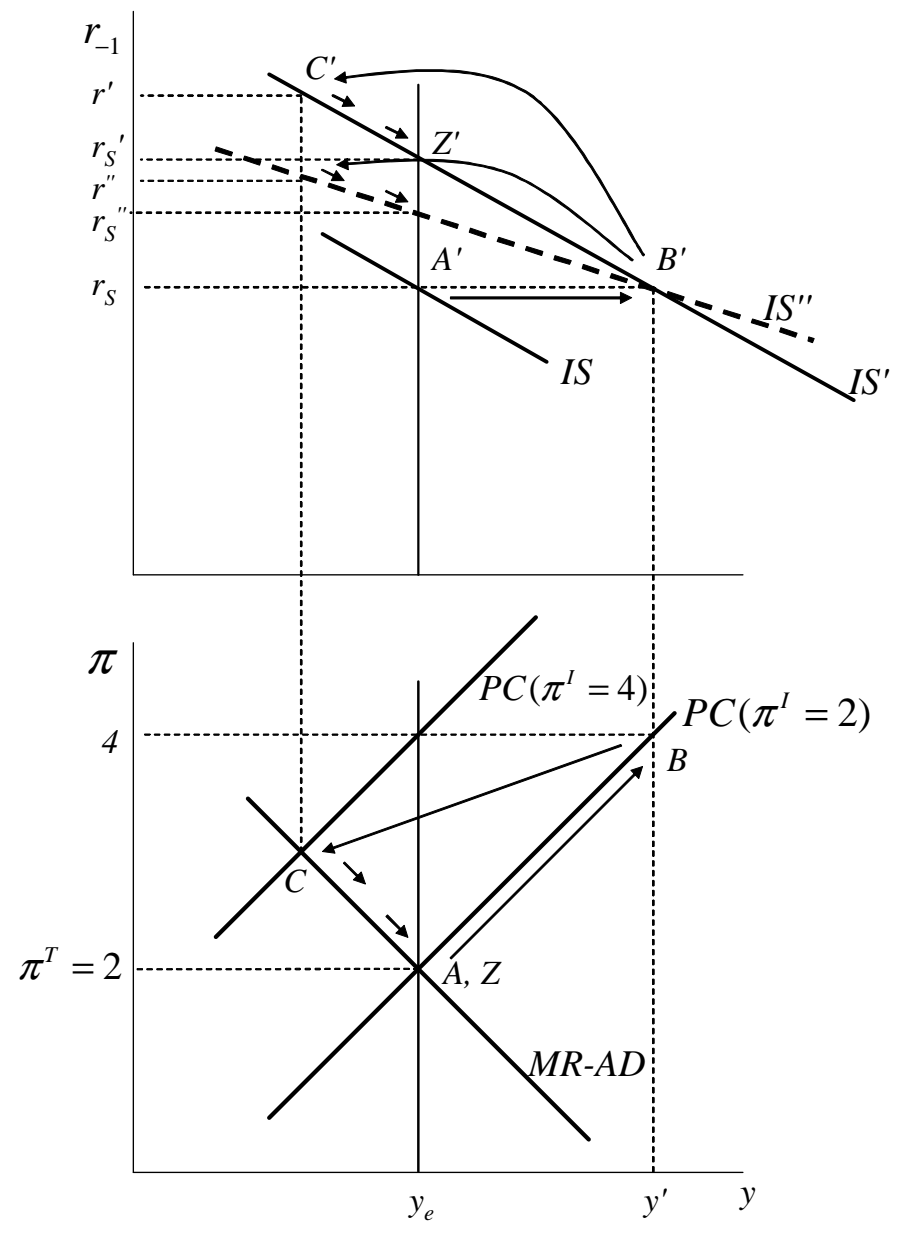

Figure 7: The monetary policy response to a permanent $I S$ shock: the role of the slope of the $I S$ 
sloping with a gradient of minus one. It follows that the $M R$ - $A D$ line will be flatter than this either if the weight on inflation in the central bank's loss function is greater than one $(\beta>1)$ or if the Phillips curves are steeper, i.e. if inflation is more responsive to a change in output $(\alpha>1)$. This is illustrated in Fig. 8 where the flatter $M R$ - $A D$ line, labelled $M R-A D^{\prime}$, in the left hand panel reflects a more inflation-averse central bank and in the right hand panel, a steeper Phillips curve. In each case the comparison is with the neutral case of $\alpha=\beta=1$.

Using the diagram underlines the fact that although the $M R$ - $A D$ curve is flatter in both cases, the central bank's reaction to a given inflation shock is quite different. In each case, the inflation shock takes the economy to point $B$ on the vertical Phillips curve. In the left hand panel, the flatter $M R-A D$ curve is due to greater inflation-aversion on the part of the central bank. Such a central bank will always wish to cut output by more in response to a given inflation shock (choosing point $D$ ) as compared with the neutral case of $\beta=1$ (where point $C$ will be chosen).

In the right hand panel, we keep $\beta=1$ and examine how the central bank's response to an inflation shock varies with the steepness of the Phillips curve. When $\alpha=1$, the central bank's optimal point is $C$, whereas we can see that if the Phillips curve is steeper (labelled $P C^{\prime}$ ), the central bank cuts aggregate demand by less (point $D$ ). The intuition behind this result is that a steeper Phillips curve means that the central bank has to 'do less' in response to a given inflation shock since inflation will respond sharply to the fall in output associated with tighter monetary policy.

The examples in Fig. 8b and Fig. 7 highlight that if we hold the central bank's preferences constant, common shocks will require different optimal responses from the central bank if the parameters $\alpha$ or $a$ differ. This is relevant to the comparison of interest rate rules across countries and to the analysis of monetary policy in a common currency area. For example in a monetary union, unless the aggregate supply and demand characteristics that determine the slope of the Phillips curve and the $I S$ curve in each of the member countries are the same, the currency union's interest rate response to a common shock will not be optimal for all members.

\section{Lags and the Taylor Rule}

An optimal Taylor Rule is a policy rule that tells the central bank how to set the current interest rate in response to shocks that result in deviations of inflation from target or output from equilibrium or both in order to achieve its objectives. In other words, $\left(r_{0}-r_{S}\right)$ responds to $\left(\pi_{0}-\pi^{T}\right)$ and $\left(y_{0}-y_{e}\right)$, for example:

$$
r_{0}-r_{S}=0.5 \cdot\left(\pi_{0}-\pi^{T}\right)+0.5 \cdot\left(y_{0}-y_{e}\right) . \quad \text { (Taylor rule) }
$$




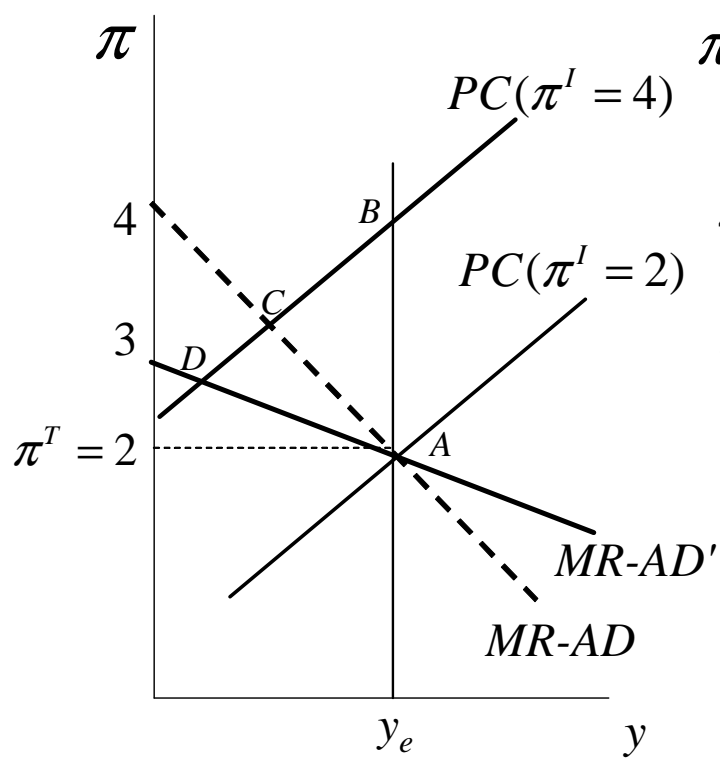

a. Greater inflation-aversion

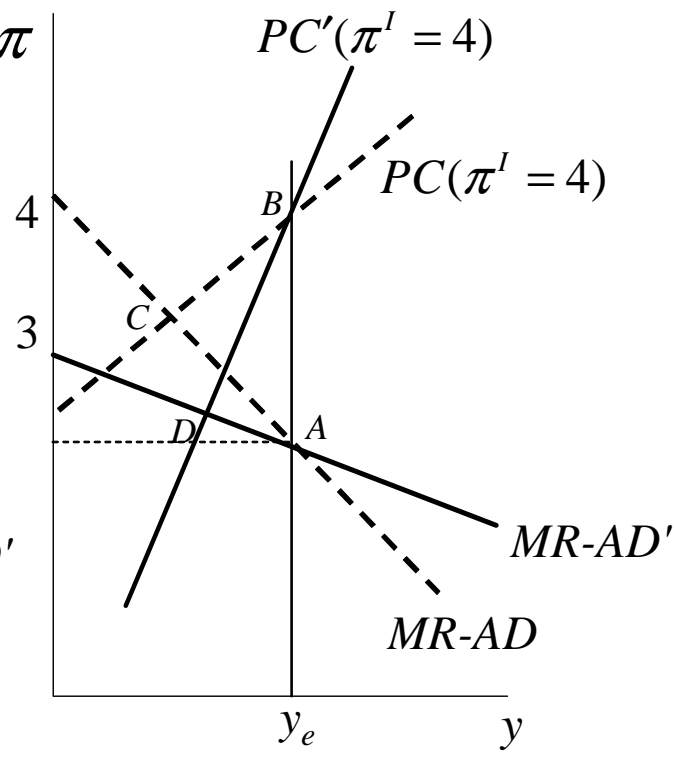

b. Steeper Phillips curve

Figure 8: Inflation shock: the effect of (a) greater inflation aversion of the central bank and (b) a steeper Phillips curve 
We have already derived the optimal Taylor-type rule for the 3-equation $\mathrm{C}-\mathrm{S}$ model:

$$
\left.\left(r_{0}-r_{S}\right)=\frac{1}{a\left(\alpha+\frac{1}{\alpha \beta}\right)}\left(\pi_{0}-\pi^{T}\right), \quad \text { (IR equation, C-S model }\right)
$$

which with $a=\alpha=\beta=1$, gives $r_{0}-r_{S}=0.5 \cdot\left(\pi_{0}-\pi^{T}\right)$. Two things are immediately apparent: first, only the inflation and not the output deviation is present in the rule and second, as we have seen in the earlier examples, all the parameters of the three equation model matter for the central bank's response to a rise in inflation. If each parameter is equal to one, the weight on the inflation deviation is one half. For a given deviation of inflation from target, and in each case, comparing the situation with that in which $a=\alpha=\beta=1$, we have

- a more inflation averse central bank $(\beta>1)$ will raise the interest rate by more;

- when the $I S$ is flatter $(a>1)$, the central bank will raise the interest rate by less;

- when the Phillips curve is steeper $(\alpha>1)$, the central bank will raise the interest rate by less.

In order to derive a Taylor rule in which both the inflation and output deviations are present, it is necessary to modify the lag structure of the three equation $\mathrm{C}-\mathrm{S}$ model. Specifically, it is necessary to introduce an additional lag: in the Phillips curve, i.e. the output level $y_{1}$ affects inflation a period later, $\pi_{2}$. This means that it is $y_{0}$ and not $y_{1}$ that is in the Phillips curve for $\pi_{1}$.

The double lag structure is shown in Fig. 9 and highlights the fact that a decision taken today by the central bank to react to a shock will only affect the inflation rate two periods later, i.e. $\pi_{2}$. When the economy is disturbed in the current period (period zero), the central bank looks ahead to the implications for inflation and sets the interest rate $r_{0}$ so as to determine $y_{1}$, which in turn determines the desired value of $\pi_{2}$. As the diagram illustrates, action by the central bank in the current period has no effect on output or inflation in the current period or on inflation in a year's time.

Given the double lag, the central bank's loss function contains $y_{1}$ and $\pi_{2}$ since it is these two variables it can choose through its interest rate decision: ${ }^{7}$

$$
L=\left(y_{1}-y_{e}\right)^{2}+\beta\left(\pi_{2}-\pi^{T}\right)^{2}
$$

\footnotetext{
$\delta=1$.

${ }^{7}$ For clarity when teaching, it is probably sensible to ignore the discount factor, i.e. we assume
} 


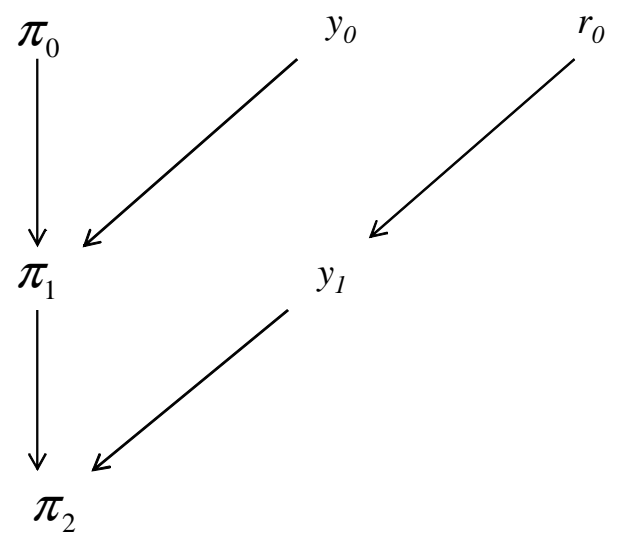

Figure 9: Double lag structure in the 3-equation model

and the three equations are:

$$
\begin{aligned}
\pi_{1} & =\pi_{0}+\alpha\left(y_{0}-y_{e}\right) \\
y_{1}-y_{e} & =-a\left(r_{0}-r_{S}\right) \\
\pi_{2}-\pi^{T} & =-\frac{1}{\alpha \beta}\left(y_{1}-y_{e}\right) .
\end{aligned}
$$

By repeating the same steps as we used to derive the interest rate rule in section 2, we can derive a Taylor rule:

$$
\left(r_{0}-r_{S}\right)=\frac{1}{a\left(\alpha+\frac{1}{\alpha \beta}\right)}\left[\left(\pi_{0}-\pi^{T}\right)+\alpha\left(y_{0}-y_{e}\right)\right] .
$$

(Interest rate (Taylor) rule in 3-equation (double lag) model)

If $a=\alpha=\beta=1$, then

$$
\left(r_{0}-r_{S}\right)=0.5\left(\pi_{0}-\pi^{T}\right)+0.5\left(y_{0}-y_{e}\right) .
$$

Implicitly the Taylor Rule incorporates changes in the interest rate that are required as a result of a change in the stabilizing interest rate (in the case of a permanent shift in the $I S$ or of a supply-side shift): $r_{S}$ in the rule should therefore be interpreted as the post-shock stabilizing interest rate. 
It is often said that the relative weights on output and inflation in a Taylor Rule reflect the central bank's preferences for reducing inflation as compared to output deviations. However, we have already seen in the single lag version of the model that although the central bank cares about both inflation and output deviations, only the inflation deviation appears in the interest rate rule. Although both the output and inflation deviations are present in the $I R$ equation for the double lag model, the relative weights on inflation and output depend only on $\alpha$, the slope of the Phillips curve. The relative weights are used only to forecast next period's inflation. The central bank preferences determine the interest rate response to next period's inflation (as embodied in the slope of the $M R$ curve). Another way to express this result is to say that the output term only appears in the $I R$ equation because of the lag from a change in output to a change in inflation.

\section{Conclusions}

The graphical 3-equation $(\mathrm{C}-\mathrm{S})$ model is a replacement for the standard $I S-L M$ $A S$ or $A D-A S$ model and has a number of features that distinguish it from other models that replace the $L M$ with a monetary policy rule. ${ }^{8}$ It conforms with the view that monetary policy is conducted by forward-looking central banks and provides undergraduate students and non-specialists with the tools for analyzing a wide range of macroeconomic disturbances. The graphical approach helps illuminate the role played by the structural characteristics on the aggregate supply and demand sides of the economy and by the central bank's preferences in determining the central bank's optimal interest rate response to shocks.

By setting out a simple version of the three-equation model, we can see the role played by frictions in the economy. An inflation shock entails costly adjustment in the economy when inflation is inertial. When aggregate demand responds to interest rate changes with a lag and inflation is inertial, the central bank will not be able to offset aggregate demand and aggregate supply shocks immediately and adjustment will therefore be costly. If, in addition, the response of inflation to output is lagged, the central bank will have to forecast the Phillips curve a further period ahead and the Taylor rule will take its familiar form to include contemporaneous inflation and output shocks. The 3 -equation $(\mathrm{C}-\mathrm{S})$ model provides access to contemporary debates in the more specialized monetary macroeconomics literature. As shown in Carlin and Soskice (2005), it is straightforward to demonstrate the origin of the time-inconsistency problem using the graphical approach.

All modeling in economics needs to be taken with a pinch of salt. Our purpose is to provide a simple tool-kit for analysing most common situations. Three conclud-

\footnotetext{
${ }^{8}$ The differences are set out in Carlin and Soskice (2005).
} 
ing remarks are important: (1) In this chapter, we do not discuss in any detail how $y_{e}$ is derived: the example shown in Fig. 5 indicates how changes in the real cost of raw materials, including food and energy, are reflected in the interaction of pricesetting and wage-setting real wage curves. The structural effects of tax changes can be shown in a similar way, as can shifts in productivity and institutional and policy characteristics of the labour and product markets. (2) Autonomous demand $A$ is probably the most difficult component to forecast particularly when household and business expectations are changing. And the ability of the $\mathrm{CB}$ to 'pick' future output by current changes in $r$ is most suspect under such volatile conditions. Finally (3) the chapter focuses on the closed economy. Although we have introduced the analysis of an oil price shock, we have not presented a full model of the open economy to include the role of exchange rate determination. As we show in our textbook (2006), the role of the real exchange rate in the open economy leads to some important changes in analysis.

\section{Appendix}

\subsection{The central bank's loss function: graphical representation}

The geometry of the central bank's loss function can be shown in the Phillips curve diagram. The loss function

$$
L=\left(y_{1}-y_{e}\right)^{2}+\beta\left(\pi_{1}-\pi^{T}\right)^{2}
$$

is simple to draw. With $\beta=1$, each 'indifference curve' is a circle with $\left(y_{e}, \pi^{T}\right)$ at its centre (see Fig. 10(a)). The loss declines as the circle gets smaller. When $\pi=\pi^{T}$ and $y=y_{e}$, the circle shrinks to a single point (called the 'bliss point') and the loss is at a minimum at zero. With $\beta=1$, the central bank is indifferent between inflation $1 \%$ above (or below) $\pi^{T}$ and output $1 \%$ below (or above) $y_{e}$. They are on the same loss circle.

Only when $\beta=1$, do we have indifference circles. If $\beta>1$, the central bank is indifferent between (say) inflation $1 \%$ above (or below) $\pi^{T}$ and output $2 \%$ above (or below) $y_{e}$. This makes the indifference curves ellipsoid as in Fig. 10(b). A central bank with less aversion to inflation $(\beta<1)$ will have ellipsoid indifference curves with a vertical rather than a horizontal orientation (Fig. 10(c)). In that case, the indifference curves are steep indicating that the central bank is only willing to trade off a given fall in inflation for a smaller fall in output than in the other two cases. 


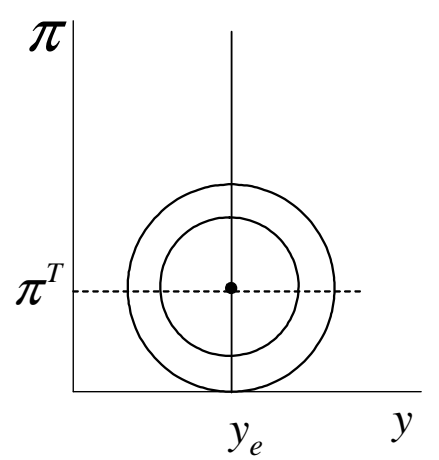

(a) Balanced: $\beta=1$

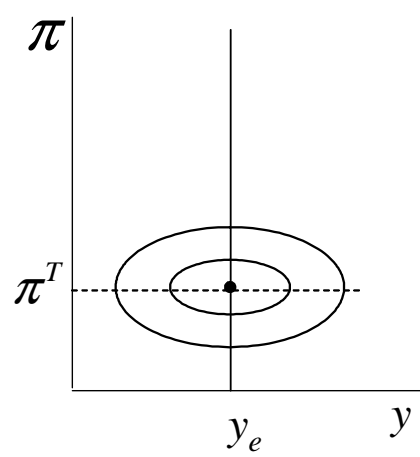

(b) Inflation-averse: $\beta>1$

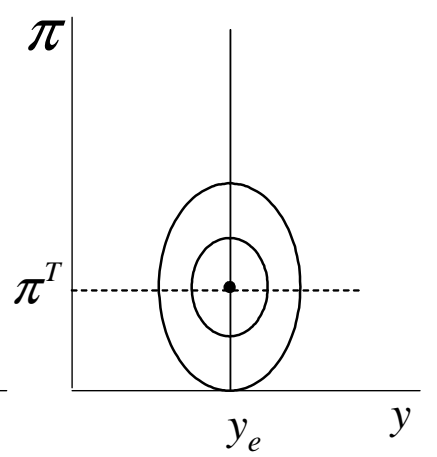

(c) Unemploymentaverse: $\beta<1$

Figure 10: Central bank loss functions: utility declines with distance from the 'bliss point' 


\section{References}

Carlin, Wendy and David Soskice (2005). 'The 3-Equation New Keynesian Model - A Graphical Exposition', Contributions to Macroeconomics, Volume 5, Issue 1, Article 13: 1-36.

Carlin, Wendy and David Soskice (2006). Macroeconomics: Imperfections, Institutions and Policies. Oxford University Press: Oxford.

Clarida, Richard, Jordi Gali and Mark Gertler (1999). 'The Science of Monetary Policy: A New Keynesian Perspective'. Journal of Economic Literature. 37(4): 1661-1707.

Gali, Jordi (2008). Monetary Policy, Inflation, and the Business Cycle: An Introduction to the New Keynesian Framework. Princeton University Press: Princeton.

Woodford, Michael (2003). Interest and Prices: Foundations of a Theory of Monetary Policy. Princeton University Press: Princeton. 